\title{
To study the role of epidural analgesia in anaemic parturients
}

\author{
Amita Chaudhary ${ }^{1}$, Amrita Singh $^{1}$, Kiran Pandey ${ }^{1}$, Anil Verma ${ }^{2}$, Sangeeta Arya $^{1}$
}

\author{
${ }^{1}$ Department of Obstetrics and Gynaecology, GSVM Medical College, Kanpur, Uttar Pradesh, India \\ ${ }^{2}$ Department of Anaesthesia, GSVM Medical College, Kanpur, Uttar Pradesh, India
}

Received: 18 June 2016

Revised: 30 September 2016

Accepted: 01 October 2016

\section{*Correspondence:}

Dr. Amrita Singh,

E-mail: amrita.5511@ rediffmail.com

Copyright: () the author(s), publisher and licensee Medip Academy. This is an open-access article distributed under the terms of the Creative Commons Attribution Non-Commercial License, which permits unrestricted non-commercial use, distribution, and reproduction in any medium, provided the original work is properly cited.

\begin{abstract}
Background: To study the safety of epidural analgesia, effect on cardiotocographic parameters, fetal outcome and obstetric outcome of epidural analgesia in anaemic parturients and maternal satisfaction as well as pain relief among antenatal cases admitted in Upper India Sugar Exchange, GSVM Medical College, Kanpur, UP, India.

Methods: This prospective study was conducted in anaemic parturients with cephalic presentation, singleton pregnancy having 36-42 weeks of gestation. Subjects of present study were divided into 2 groups. Control group included anaemic parturients not undergoing epidural analgesia. Study group included anaemic parturients who will be undergoing epidural analgesia. All these patients were followed up to delivery. When cervix was $3 \mathrm{~cm}$ dilated, NST was taken 15 minutes before analgesia and every 30 minutes after analgesia. Top up dose $(0.0625 \%$ bupivacaine $)$ was injected through catheter on parturients demand. For effect on CTG parameters, NST was taken 15 minutes before analgesia and every 30 minutes after analgesia. Following every top up dose 10 minute monitoring for uterine contractions and effect for adequate analgesia was noted. Side effects and complaints noted at 5, 15, 30, 45, 60, 90, 120, 150 and $180 \mathrm{~min}$ interval. Fetal condition was also monitored and evidence of fetal distress, on clinical and/or cardiotocographic monitoring, was recorded. Patients walking duration was recorded in relation to study time from epidural insertion to delivery time. Labour was managed and mode of delivery and time of delivery was noted. Assessment of neonatal outcome was done with the help of Apgar scoring at 1 and 5minute after delivery and NICU admissions.
\end{abstract}

Results: Maximum numbers of patients are lying between age groups of 18-23 and 24-29 years and are of gestational age group 37-40 weeks in both study and control group. The duration of 1st stage of labour in maximum number of primigravida patients is 5-8 hours and in multigravida it was 2-4 hours in both epidural and control group. The visual analogue scale is according to pain perceived during the course of labour and delivery by the epidural and control group. The degree of pain relief is statistically highly significant between epidural and control groups. Occurrences of maternal tachycardia are 5 times more in cases in whom epidural analgesia was not given.

Conclusions: There is no statistically significant difference in the duration of 2 nd stage of labour in both the groups of primigravida as well as there is no effect on the duration of second stage of labour in multigravida parturients in both the groups. Pain relief was more in the epidural group and was more satisfied after their delivery. There was no difference in effect on fetal outcome in epidural and control groups. There was no significant effect on cardiotocographic parameters except for the fact that for about 30 minutes post epidural top-up, there was fetal bradycardia which easily subsided with conservative management with left lateral position and oxygen. Maternal tachycardia was less in epidural group. This was highly significant because anaemic parturients are more prone to develop signs of cardiac failure during labour due to increase in stroke volume due to increase in heart rate due to pain.

Keywords: Cardiotocographic, Epidural analgesia, Maternal tachycardia 


\section{INTRODUCTION}

"The only thing as consistent as birth pain has been the success to eradicate it, pharmaceutically" - Tina Cassidy. Pain relief is of immense importance for a parturient as it influences a woman's satisfaction with labour and delivery and has immediate and long-term emotional and psychological effects and also influences breastfeeding and emotional bonding between mother and baby. Several methods of relieving labour pain have been described, ranging from limited intervention such as breathing exercises to medical techniques like epidural analgesia. The utmost important issue is that whatever method is used to relieve the parturating mother of the severe pain, it should be both effective and safe for the mother as well as the baby. Epidural analgesia was first used in obstetric practice in 1946 and its use in labour has steadily increased until the last decade. Epidural analgesia is a central nerve blockade technique, which involves the injection of a local anaesthetic into the lower region of the spine close to the nerves that transmit painful stimuli from the contracting uterus and birth canal. The anaesthesia inhibits nerve conduction by blocking sodium channels in nerve membranes, thereby preventing the propagation of nerve impulses along these fibres. It exerts a concentration specific effect, affecting all the modalities of sensation of the blocked nerves to varying degrees, such that administration of a lower-dose anaesthetic (e.g. $0.0625 \%$ bupivacaine) partially but selectively blocks painful stimuli while preserving motor function, whereas higher doses of anaesthetic afford complete sensory and motor blockade limiting mobility in labour. Blocking of sympathetic nerves occurs at varying concentrations and associated with vasodilatation and hypotension as well. ${ }^{1}$

We have restricted the preload before epidural catherisation in anaemic subjects but have not withheld preload completely, as preload if not given can lead to hypotension and at the same time, excess preload can precipitate congestive cardiac failure in severely anaemic subjects.

\section{METHODS}

This prospective study was conducted in Upper India Sugar Exchange Maternity Hospital, Department of Obstetrics and Gynaecology, from February 2013 to August 2014, GSVM Medical College, Kanpur. Cases included were 120 anaemic parturients, 36-42 weeks gestation, and singleton pregnancy with cephalic presentation.

Patients with Pre-eclampsia, Diabetes, Preterm labour, Bleeding disorders, Scoliosis, Morbid obesity, Allergy to study drug, Blood in CSF in epidural catheter were excluded. Subjects of present study were divided into 2 groups: Control group $(\mathrm{N}=60)$ included anaemic parturients not undergoing epidural analgesia. Study group ( $\mathrm{N}=60)$ included anaemic parturients who will be undergoing epidural analgesia. Written informed consent was obtained and all these patients were followed up to delivery. All the patients selected were studied in detail with regard to clinical history, general examination, local examination and basic investigations. Per speculum examination and per vaginal examination was done as required. All patients included in study were followed up to postnatal period.

Non-stress test was done in all patients undergoing epidural analgesia labour and fetal outcome was noted in all these patients. An intravenous line was secured and a preload of 500ml of Hartmann's (RL) solution was given placing them in left lateral position. In patients with severe anaemia with signs of cardiac decompensation, preload was given carefully and stopped if there were signs of cardiac failure. When cervix was $3 \mathrm{~cm}$ dilated, NST was taken 15 minutes before analgesia and every 30 minutes after analgesia. Top up dose $(0.0625 \%$ bupivacaine) was injected through catheter on parturients demand. Following every top up dose 10 minute monitoring for uterine contractions, and effect for adequate analgesia was done. Side effects and complaints noted at 5, 15, 30, 45, 60, 90, 120, 150 and $180 \mathrm{~min}$ interval. Complications related to epidural analgesia were observed. Time to the first top dose and additional analgesia required by the mother was recorded. Patients walking duration was recorded in relation to study time from epidural insertion to delivery time. Labour was managed and mode of delivery and time of delivery was noted. Assessment of neonatal welfare was done with the help of Apgar scoring at 1 and 5 minute after delivery and NICU admissions.

\section{RESULTS}

Mean haemoglobin in study group $6.9783 \mathrm{~g} \%$. Mean haemoglobin in control group $7.1083 \mathrm{~g} \%$.

Table 1: Administration - onset of analgesia interval.

\begin{tabular}{|lll|}
\hline Time (minute) & $\mathrm{N}=60$ & $\%$ \\
\hline 8 & 3 & 5 \\
\hline 10 & 11 & 18.3 \\
\hline 12 & 21 & 35 \\
\hline 15 & 21 & 35 \\
\hline$>15$ & 4 & 6.7 \\
\hline
\end{tabular}

Mean analgesia interval $=12.93 \pm 2.69882 \mathrm{~min}$

Table 2: Duration of 1st stage of labour in study and control groups (hours) mean \pm sd.

\begin{tabular}{|llll|}
\hline & $\begin{array}{l}\text { Epidural group } \\
(\mathrm{n}=60)\end{array}$ & $\begin{array}{l}\text { Control group } \\
(\mathrm{n}=60)\end{array}$ & $\begin{array}{l}\text { P- } \\
\text { value }\end{array}$ \\
\hline $\begin{array}{l}\text { Primi- } \\
\text { gravida }\end{array}$ & $5.8594 \pm 0.9774$ & $5.5806 \pm 1.05316$ & 0.508 \\
\hline $\begin{array}{l}\text { Multi- } \\
\text { gravida }\end{array}$ & $3.6613 \pm 0.8345$ & $4.2411 \pm 0.7559$ & 0.602 \\
\hline
\end{tabular}


By applying independent samples $\mathrm{t}$ - test, $\mathrm{p}$ - value for first stage of labour in primigravida and multigravida was $>0.05$. This shows that there was no statistically significant association in the duration of 1st stage of labour between study group and control group in primigravida as well as multigravida.

\section{Table 3: Duration of $2^{\text {nd }}$ stage of labour (hours) mean \pm sd.}

\begin{tabular}{|llll|}
\hline & $\begin{array}{l}\text { Epidural group } \\
(\mathrm{n}=60)\end{array}$ & $\begin{array}{l}\text { Control group } \\
(\mathrm{n}=60)\end{array}$ & $\begin{array}{l}\mathrm{P} \text { - } \\
\text { value }\end{array}$ \\
\hline $\begin{array}{l}\text { Primi- } \\
\text { gravida }\end{array}$ & $0.9441 \pm 0.45480$ & $0.7747 \pm 0.4234$ & 0.848 \\
\hline $\begin{array}{l}\text { Multi- } \\
\text { gravida }\end{array}$ & $0.3829 \pm 0.14352$ & $0.4843 \pm 0.2249$ & 0.067 \\
\hline
\end{tabular}

By applying independent samples t- test, $\mathrm{p}$ - values for both primigravida and multigravida in study and control groups were $>0.05$. This shows that there was no statistically significant difference in the duration of 2 nd stage of labour between study and control groups.

Table 4: Distribution of parturients according to mode of delivery.

\begin{tabular}{|lllll|}
\hline & $\begin{array}{l}\text { Epidural } \\
\text { group } \\
(\mathrm{n}=60)\end{array}$ & $\%$ & $\begin{array}{l}\text { Control } \\
\text { group } \\
(\mathrm{n}=60)\end{array}$ & $\%$ \\
\hline $\begin{array}{l}\text { Normal } \\
\text { vaginal }\end{array}$ & 53 & 88.3 & 54 & 90 \\
\hline Assisted & 1 & 1.7 & 2 & 3.3 \\
\hline Caesarean & 6 & 10 & 4 & 6.7 \\
\hline
\end{tabular}

Table 4 shows distribution of patients according to mode of delivery. There was no difference in the rate of assisted delivery and caesarean section in both epidural and control group.

Table 5: Distribution of parturients according to visual analogue score.

\begin{tabular}{|lllll|}
\hline Vas score & $\begin{array}{l}\text { Epidural } \\
\text { group (n) }\end{array}$ & $\%$ & $\begin{array}{l}\text { Control } \\
\text { group (n) }\end{array}$ & $\%$ \\
\hline $1-2$ & 21 & 35 & - & \\
\hline $3-4$ & 35 & 58.3 & - & \\
\hline $5-6$ & 4 & 6.7 & 12 & 20 \\
\hline $7-8$ & - & & 40 & 66.7 \\
\hline $9-10$ & - & & 8 & 13.3 \\
\hline
\end{tabular}

Mean pain scores in Primigravida is $3.1250 \pm 0.70711$ in study group while it is $8.4688 \pm 0.76314$ in control group and that of Multigravida are 2.1429 \pm 0.35635 in study and $7.3929 \pm 0.78595$ in control group. By applying independent samples $\mathrm{t}-$ test, $\mathrm{P}=0.0001$ in both primigravida and multigravida which is statistically highly significant. The subjects in epidural group perceived less pain during their labour. They were more satisfied after their delivery.

\section{DISCUSSION}

In our study conducted on 120 anaemic patients, 60 opted for epidural analgesia and another 60 opted no analgesia. In study group, 60 patients 32 were primigravida and 28 multigravida.

The mean haemoglobin was $6.9783 \mathrm{~g} \%$ in epidural group and $7.1083 \mathrm{~g} \%$ in control group. Most parturients were in the gestational age of 37 to 40 weeks.

By applying independent samples t-test the mean duration of $1^{\text {st }}$ stage of labour in primigravida was $5.8594 \pm 0.9774$ hours in epidural group and $5.5806 \pm 1.0531$ hours in control group, $\mathrm{t}=2.38, \mathrm{p}>0.508$ which proves there was no statistically significant difference. The mean duration of first stage of labour in multigravida was $3.6613 \pm 0.8345$ hours in epidural group and 4.2411 \pm 0.7559 hours in control group, $\mathrm{p}=0.602, \mathrm{t}=$ 1.097 which is again not statistically significant. According to our study there was no statistically significant difference between duration of labour of $1^{\text {st }}$ stage of labour in primigravida and multigravida (Table 2). Mousa WF et al studied the effect of epidural analgesia on the duration of labor in primiparous parturients and found that epidural analgesia may accelerate labour as the provision of effective analgesia reduces maternal catecholamine's, and hence minimizing its inhibitory effect on uterine contractility. ${ }^{2}$

By applying independent samples t- test, the duration of second stage of labour in primigravida was $0.9441 \pm 0.45480$ hours in epidural group and $0.7747 \pm 0.4234$ hours in control group. $t=1.542, \mathrm{p}=$ 0.848 , there was no statistically significant difference. The duration of second stage of labour in multigravida was $0.3829 \pm 0.14352$ hours in epidural group and $0.4843 \pm 0.22409$ hours in control group $(\mathrm{t}=2.017, \mathrm{p}=$ 0.067). There is again no statistically significant difference in second stage of labour between both the groups (Table 3).

The mean pain score in epidural group was $2.6667 \pm 0.62887$ and $7.6500 \pm 1.02221$ in control group $(\mathrm{p}=0.0001, \mathrm{t}=32.163$, mean difference $=4.98333)$. Among primigravida patients it was $3.1250 \pm 0.70711$ in study group and $8.4688 \pm 0.76134$ in control group $(\mathrm{t}=$ 29.093, $\mathrm{p}=0.0001)$. The mean pain score among multigravida was $2.1429 \pm 0.35635$ in epidural group and $7.3929 \pm 0.78595$ in control group $(\mathrm{t}=32.192, \mathrm{p}=0.0001)$. The degree of pain relief is statistically highly significant between epidural and control groups.

There was no difference in effect on fetal outcome in epidural and control groups. There was no significant effect on cardiotocographic parameters except for the fact that for about 30 minutes post epidural top up, there was 
fetal bradycardia which easily subsided with conservative management with left lateral position and oxygen.

Reynolds F studied the effects of maternal labour analgesia on the fetus and found that Apgar score is better after epidural than systemic opioid analgesia, while neonatal acid-base balance is improved by epidural compared to systemic analgesia and even compared to no analgesia. $^{3-5}$

Table 6: Apgar score at $1 \mathrm{~min}$, Apgar score at $5 \mathrm{~min}$.

\begin{tabular}{|lllll|llll|}
\hline & Epidural group & $\%$ & Control group & $\%$ & Epidural group & $\%$ & Control group & $\%$ \\
\hline$>7$ & 40 & $67 \%$ & 43 & $72 \%$ & 51 & $85 \%$ & 53 & $88 \%$ \\
\hline $4-7$ & 14 & $23 \%$ & 11 & $18 \%$ & 4 & $6.7 \%$ & 2 & $3.3 \%$ \\
\hline$<4$ & 6 & $10 \%$ & 6 & $10 \%$ & 5 & $8.3 \%$ & 4 & $6.7 \%$ \\
\hline
\end{tabular}

There was no difference in mode of delivery between epidural and non-epidural groups. Nafisi $\mathrm{S}$ et al found that there was no statistical difference in rates of vacuumassisted delivery rate and caesarean deliveries, differences in the duration of the active-first and the second stages of labor. ${ }^{6-8}$

Occurrence of maternal tachycardia was 5 times more in cases in which epidural analgesia was not given. This was highly significant because anaemic parturients are more prone to develop signs of cardiac failure during labour due to increase in stroke volume due to increase in heart rate due to pain.

There was no incidence of postpartum haemorrhage among the study group while among controls, 3 parturients had postpartum haemorrhage. During intrapartum and immediate postpartum period, none of the parturient in study group had cardiac failure nor needed ICU care but amongst controls, 2 parturients went into cardiac decompensation due to haemodynamic effects of severe anaemia and needed ICU care for vitals management. In the postpartum period, parturients in study group had successful establishment of breastfeeding within half an hour of delivery. Parturients were managed according to their anaemic status (mild, moderate, severe anaemia) with blood transfusion or parenteral or oral iron therapy and were discharged with good maternal and fetal outcome. Doshi HU et al found that EA is a very safe and effective form of analgesia in the interest of maternal and fetal welfare not only in normal pregnant gravidas, but also in high risk patients. ${ }^{9}$

\section{CONCLUSION}

Maximum numbers of patients are lying between age groups of 18-23 and 24-29 years in and are of gestational age group 37-40 weeks in both study and control group. The duration of 1st stage of labour in maximum number of primigravida patients is 5-8 hours in both epidural group and control group. The duration of 1st stage of labour in multigravida in the maximum number of patient is 2-4 hours in both epidural and control group. This implies that there is no statistically significant difference in the duration of 2 nd stage of labour as well as in the duration 0f 1st stage in both the groups. As per the mean pain score the degree of pain relief is statistically highly significant in epidural than in control groups. They were more satisfied after their delivery. There was no difference in effect on fetal outcome in epidural and control groups. There was no significant effect on cardiotocographic parameters except for the fact that for about 30 minutes post epidural top-up, there was fetal bradycardia which easily subsided with conservative management with left lateral position and oxygen. Occurrences of maternal tachycardia are 5 times more in cases in whom epidural analgesia was not given. This was highly significant because anaemic parturients are more prone to develop signs of cardiac failure during labour due to increase in stroke volume due to increase in heart rate due to pain. There was no incidence of postpartum haemorrhage among the study group while among controls, 3 parturients had postpartum haemorrhage. During intrapartum and immediate postpartum period, none of the parturient in study group had cardiac failure nor needed ICU care but amongst controls, 2 parturients went into cardiac decompensation due to haemodynamic effects of severe anaemia and needed ICU care for vitals management. In the postpartum period, parturients in study group had successful establishment of breastfeeding within half an hour of delivery. Parturients were managed according to their anaemic status (mild, moderate, severe anaemia) with blood transfusion or parenteral or oral iron therapy and were discharged with good maternal and fetal outcome.

Funding: No funding sources Conflict of interest: None declared

Ethical approval: The study was approved by the Institutional Ethics Committee

\section{REFERENCES}

1. McGrady E, Litchfield K. Epidural analgesia in labour. Contin Educ Anaesth Crit Care Pain. Oxford Journals. 2004;4(4):114-7.

2. Al-Metwalli R, Mostafa M. Epidural analgesia during labor vs no analgesia: A comparative study Saudi J Anaesth. 2012;6(1):36-40. 
3. Reynolds F, Sharma SK, Seed PT. Analgesia in labour and fetal acid-base balance: a meta-analysis comparing epidural with systemic opioid analgesia. BJOG. 2002;109(12):1344-53.

4. Reynolds F. The effects of maternal labour analgesia on the fetus. Best Pract Res Clin Obstet Gynaecol. 2010;24(3):289-302.

5. Howell CJ. Epidural versus non-epidural analgesia for pain relief in labour. Cochrane Database Syst Rev. 2000;2:CD000331.

6. Nafisi S. Effects of epidural lidocaine analgesia on labor and delivery: a randomized, prospective, controlled trial. BMC Anesthesiol. 2006;18;6:15.

7. Fung BK. Continuous epidural analgesia for painless labor does not increase the incidence of cesarean delivery. Acta Anaesthesiol Sin. 2000;38(2):79-84.

8. Zhang J, Klebanoff MA, DerSimonian Epidural analgesia in association with duration of labor and mode of delivery: a quantitative review. Am J Obstet Gynecol. 1999;180(4):970-7.
9. Doshi HU, Tarlika P, Gupta AG. Epidural Analgesia in High Risk Patients during Labour. JK Sci. 2009;11(3):130-2.

10. Pain relief during labor. American College of Obstetricians and Gynecologists. Obstet Gynecol 2004;104:213. ACOG Committee Opinion No. 295.

11. Costley PL, East CE. Oxytocin augmentation of labour in women with epidural analgesia for reducing operative deliveries. Cochrane database of systematic reviews, Cochrane Pregnancy and Childbirth Group, 2013. DOI: 10.1002/14651858.CD009241.

12. Kumar M, Chandra S, Ijaz Z, Senthilselvan A. Epidural analgesia in labour and neonatal respiratory distress: a case-control study. Arch Dis Child Fetal Neonatal Ed. 2014;99(2):F116-9.

Cite this article as: Chaudhary A, Singh A, Pandey K, Verma A, Arya S. To study the role of epidural analgesia in anaemic parturients. Int J Reprod Contracept Obstet Gynecol 2016;5:3859-63. 